\title{
Proposal of Meta-Evaluation in the Computer Engineering Career of the Distance State University of Costa Rica
}

\author{
Aurora Trujillo Cotera, Ing. Ariana Acón Matamoros \\ Universidad Estatal a Distancia (UNED), San José, Republic of Costa Rica
}

\begin{abstract}
The Mission of the Academic Quality Management Institute (Instituto de Gestión de la Calidad Académica, IGESCA) of the Distance State University (Universidad Estatal a Distancia, UNED) is to promote the culture of quality through research, dissemination, and development of systems and indicators. In addition, it is in charge of providing counseling in the self-assessment processes of undergraduate and postgraduate programs aimed at obtaining the accreditation of academic excellence required by the National Accreditation System for Higher Education (SINAES) in Costa Rica. On February 21 in 2017, the computer engineering career received an accreditation certificate for the following: (a) diploma and bachelor's in computer engineering; (b) bachelor's degree (licenciatura) in computer engineering; (c) bachelor's degree (licenciatura) in computer science and software quality; (d) bachelor's degree (licenciatura) in computer science and project management; and (e) bachelor's degree (licenciatura) in computer engineering and web application development. The career as a whole was awarded in an official ceremony held in the central facilities of the UNED, where the authorities participated. Accreditation by SINAES was done according to Agreement-National Accreditation Council (CAN) -393-2016, in session on October 14, 2016 through Act 1089-2016 and ratified on November 4, 2016. SINAES accreditation is paradoxical for the Computer engineering career. The self-evaluation processese stablished by an accrediting agency to publicly certify that the career has quality criteria represent an end and a beginning as well. It is the end of a a strenuous period of facing difficult work processes of the career staff accompanied by the IGESCA adviser and receiving external evaluation of three specialists in the field (academic pairs), two international professionals and a national one, who verify that the career complies with the criteria and standards of the SINAES Accreditation Manual and recommend its accreditation, so that it can subsequently be approved by the SINAES Council, and thus, receive the accreditation certificate. It is the beginning of a new stage: the fulfillment of improvement actions incorporated in the commitment resulting from the self-evaluation, to turn the weaknesses into improvement opportunities and to maintain tested standards for the purpose of continuous improvement. This is why it is important to evaluate the self-assessment of the degree courses, in this case, the computer engineering career, always in search of quality, validity, reliability, and continuous improvement. It is here where the term meta-evaluation is referred both as a higher level and a new concept of institutional evaluation.
\end{abstract}

Keywords: meta-evaluation, evaluation, self-evaluation, careers, improvement and quality

\footnotetext{
Aurora Trujillo Cotera, Dr., adviser, Academic Quality Management Institute, Universidad Estatal a Distancia (UNED). Ing. Ariana Acón Matamoros, Master, professor, School of Exact and Natural Sciences, Universidad Estatal a Distancia (UNED).
} 


\section{The General Objective}

The main objective of this article is to present a meta-evaluation proposal to apply in the Computer Engineering Career (PROING) of the School of Exact and Natural Sciences (ECEN) of the Distance State University (UNED).

It is important to contextualize some key aspects for a better understanding of this paper. These are detailed below.

1. Costa Rica is a country located in central America. It has an extension of $51,100 \mathrm{~km}^{2}$, its official language is Spanish and it has a current population of 4,920,838, of which $2,497,854$ are males $(50.8 \%)$ and 2,422.984 females (49.02\%) (Population of Costa Rica, 2017).

2. Costa Rica has five public universities: the University of Costa Rica (UCR), the National University of Costa Rica (UNA), the Technological Institute of Costa Rica (TEC), the UNED, and the National Technical University (UTN). In the private sphere, the operation of the first institution, the Autonomous University of Central America (UACA), was authorized in 1975, according to the official Information of the State of the Nation in 2015. The number of private higher education institutions has increased to 53.

\section{Laws of Creation of National Accreditation System for Higher Education}

By mandate of laws of the Republic, National Accreditation System for Higher Education (SINAES) is the official accreditation body of higher education in Costa Rica. It has a nationwide character with the highest public authority in the field of career accreditation and university higher education. It is the only body empowered to attest to the quality of those careers and programs. The criteria and standards defined by the SINAES have the official character of national academic standards of quality (SINAES, 2017).

\section{Law 8256: Law of the SINAES}

This law confers to SINAES - the category of public interest agency, whose primary mission is to officially accredit university careers and programs that meet the quality requirements established by SINAES (La Gaceta, 2002).

The law grants legal independence to SINAES recognizing it is status as a "system" and its "national" character as well as its legal nature as part of the Costa Rican state higher education system that enjoys autonomy. Therefore, SINAES is given public authority to have its own organization and government.

It grants instrumental legal status, which empowers it to acquire rights and contract obligations independently, thus conferring on SINAES the highest public authority in matters of accreditation and giving official character to its decisions.

\section{Law No. 8798: Strengthening of the SINAES}

Among its most outstanding elements, Law No. 8798 provides that the criteria and standards defined by the SINAES will have the character of a national quality academic standard. It broadens higher education competences and grants SINAES permanent, solid and secure financing. It also establishes that the Costa Rican State and its institutions will select and hire preferably the personnel graduated from officially accredited careers by the SINAES (La Gaceta, 2010).

\section{The Distance State University}

The UNED of Costa Rica is created as a response to both the increasing demand for higher education in 
the country, a consequence of the demographic expansion of the mid 20th century, and the aspirations of new sectors of the population (UNED, 2004, p. 5).

According to Acón and Cañipa (2017), it was decided to found a state university with the distance modality, according to the models of the UNED of Spain and the Open University of Great Britain. The State Distance University was created as an institution of higher education specializing in education through the social media (Article 1), through Law No. 6044, published in La Gaceta No. 50 of March 12, 1977 (UNED, 2004, p. 5).

As UNED grew with an increasing number of careers and programs, student population also increased in such a way that a culture of education quality became necessary. That is the reason why part of the university efforts is focused on accrediting careers.

The UNED meets the challenge of developing evaluative processes for the continuous improvement and accreditation of academic programs. This challenge involved developing evaluative processes different from those that were being developed, and the following aspects were considered:

1. An evaluative approach based on self-evaluation of careers and graduate programs, where the different actors, academics, administrators, students, graduates, and employers take direct responsibility of these processes giving an evaluation of their educational program;

2. A systemic, participatory, democratic, and consensual process;

3. A more comprehensive vision of an academic distance education program.

\section{Acredited Careers Towards a Culture of Quality}

The Mission of the Academic Quality Management Institute (Instituto de Gestión de la Calidad Académica, IGESCA) is attached to the academic vice-chancellery and has the mission of promoting the culture of quality through research, diffusion and development of systems and indicators, techniques of instruments, and models of procedural methods.

As part of its commitment to the quality management of UNED, the IGESCA gives advice on the self-assessment processes, the evaluation of subjects, and evaluation of didactic units. Its electronic magazine Quality in Higher Education is available to the university community (see https://www.uned.ac.cr/academica/ igesca/inicio).

The Computer Engineering Career belongs to the School of Exact and Natural Sciences (ECEN). One of its objectives is to prepare professionals who are able to contribute to the development of the software industry (Informatics Career, 2017).

Starting in 2008, they began to accredit degrees in the Distance State University, currently counting 19, of which 11 are re-accredited and two accredited postgraduate programms. Among of these, 20 are certified by SINAES and one by the Central American Postgraduate Accreditation Agency (ACAP, Agencia Centroamericana de Acreditación de Postgrados).

Once, the situation of Costa Rica has been contextualized in relation to university higher education, UNED and accreditations, we continue with aspects relevant to the project we present.

\section{Meta-Evaluation}

For the purposes of this research, the meta-evaluation is understood as the systematic assesment of the self-evaluation processes carried out by the careers in order to systematize the experience in the relevant 
aspects that are listed as below:

1. Quality of the evaluation team;

2. Level of participation during the self-evaluation process;

3. Planning and organization;

4. Commitment with which the self-assessment was carried out;

5. Construction characteristics of the report;

6. Elements that allow self-evaluation processes to be sustainable over time;

7. Decision making.

This article describes the answer to the question on how is it planned to implement and carry out the meta-evaluation proposal for the Computer Engineering Career and its different areas. To address this question, an introduction to the topic is provided.

\section{A Review of the Origin and Development of the Concept of Meta-Evaluation}

According to Stufflebeam (2011), evaluation is determining whether objectives have been achieved. It focuses on results and on determining the value of those results (p. 105). It is also important to define the term "self-assessment." According to SINAES in its official accreditation model for higher education,

Self-evaluation is the stage of the official accreditation process in which the university community, by means of a self-study that includes a participative and active reflection process, poses itself as an object of study, explores, analyzes, diagnoses, verifies, describes, and values its reality in each of its organic, academic, and administrative structures. (p. 22)

Self-evaluation is part of a systematic, participatory process of reflection, self-criticism, and analysis, taking into account the context, perceptions, opinions, and evaluations of the actors involved (students, academic and administrative staff, and academic collaborators). It values the quality within each educational program, as well as the results, with the sole purpose of formulating and carrying out proposals for continuous improvement.

According to Garcia (2000, as cited in Elizalde, Lopez, \& Olvera, 2008), the term "meta-evaluation" dates from the sixties and was started by Michael Scriven. Following with Elizalde, Lopez, and Olvera (2008), meta-evaluation has been and is commonly conceptualized as that systematic investigation whose objective is to make a judgment about the quality, relevance, pertinence, or merits of an evaluation. In addition, Garcia (2000, as cited in Elizalde, Lopez, \& Olvera, 2008), evaluation becomes the object of study of the meta-evaluator (Stufflebeam, 1981; García, 2000, as cited in Scriven, 1967, 1991).

Stufflebeam (2011) defined it as an evaluation of the evaluation, but also as a procedure for describing an evaluation activity and judging it against a set of ideas concerning what constitutes good evaluation (p. 135). Stufflebeam (2011) presented a structure for the meta-evaluation that contains eight premises and compares it with evaluation, which is summarized in Table 1.

According to Stufflebeam (2011),

Meta-evaluation should serve decision-making and accountability, and requires to be done proactively to provide timely recommendations concerning how evaluations studies should be designed and conducted. The second purpose is to serve the evaluator's need to be accountable for his work. It requires to be conducted retroactively to produce public judgment of the merits of the completed evaluation work. (p. 138) 
Table 1

Comparison Between Evaluation and Meta-Evaluation

\begin{tabular}{|c|c|c|}
\hline & Evaluation & Meta-evaluation \\
\hline 1 & Assessment of merit & Assesing the merit of evaluation efforts. \\
\hline 2 & Serves decision making and accountability & $\begin{array}{l}\text { Should provide information proactively to support the } \\
\text { decisions that must be made in conducting evaluation work. } \\
\text { Meta-evaluation should be both formative and summative. }\end{array}$ \\
\hline 3 & $\begin{array}{l}\text { Should assess goals, designs, implementation, and } \\
\text { results }\end{array}$ & $\begin{array}{l}\text { Should assess the importance of evaluation objectives, the } \\
\text { appropriateness of evaluation designs, the adequacy of } \\
\text { implementation of the designs, and the quality and } \\
\text { importance of evaluation results. }\end{array}$ \\
\hline 4 & $\begin{array}{l}\text { Should provide descriptive and judgmental information } \\
\text { and appropriate recommendations }\end{array}$ & $\begin{array}{l}\text { Should describe and judge evaluation work and should } \\
\text { recommend how the evaluations can be improved and how } \\
\text { the findings can appropriately be used. }\end{array}$ \\
\hline 5 & $\begin{array}{l}\text { Should serve every person involved in and affected by } \\
\text { the program being evaluated }\end{array}$ & $\begin{array}{l}\text { Should serve evaluators and every person interested in their } \\
\text { work. }\end{array}$ \\
\hline 6 & $\begin{array}{l}\text { Should be conducted by both insiders (formative for } \\
\text { decision-making) and outsiders (summative for } \\
\text { accountability) }\end{array}$ & $\begin{array}{l}\text { Evaluators should conduct formative metaevaluationto obtain } \\
\text { external judgments of the overall merit of their completed } \\
\text { evaluation activities. }\end{array}$ \\
\hline 7 & $\begin{array}{l}\text { Involves the process of delineating the questions to be } \\
\text { addressed obtaining the needed information and using it } \\
\text { in decision-making and accountability }\end{array}$ & $\begin{array}{l}\text { Implements three steps: delineate the specific metaevaluation } \\
\text { questions to be addressed, collect, organize and analyze the } \\
\text { needed information, andapply the information obtained to the } \\
\text { appropriate decision-making and accountability tasks. }\end{array}$ \\
\hline 8 & Must be technically adequate, useful, and cost/effective & Must satisfy the same criteria. \\
\hline
\end{tabular}

Note. Stufflebeam (2011).

Continuing with this approach, the four objects of metaevaluation which Stufflebeam (2011, pp. 138-139) pointed out are the following:

1. Evaluation goals;

2. Evaluations designs;

3. Evaluations processes;

4. Evaluation results.

These four objects define the meta-evaluation scheme and divide it into processes. Another definition is given by the editors Díaz and Rosales (2003) who stated that meta-evaluation is a social process of learning which requires that the meta-evaluator raise questions, suggestions, and perspectives that feed the understanding of evaluators and the audience (p. 44).

The meta-evaluation includes the analysis, interpretation, explanation, and scientific systematization in the theoretical and practical areas of the following elements:

1. The evaluation process, from design to presentation, including all activities;

2. Evaluation results or outputs: the evaluation document or report as well as the content of the document and its presentation and public discussion;

3. Evaluators or subjects who perform the evaluation (their behavior as spokespersons for their own work);

4. The models and types that are used as reference for carrying out the evaluation;

5. The methodology and epistemology that feed the models of evaluation and the conception of the world and the prevailing scientific paradigms, that is to say, the ideology and the philosophy on which the approach is based (p. 42).

The next section refers to the meta-evaluation in the processes of self-evaluation and accreditation. 


\section{Meta-Evaluationin the Self-Evaluation and Accreditation Processes}

Planning, execution, evaluation, and control (follow-up) are the four steps of the administration, which in turn are applied in the self-evaluation processes, because of their characteristics. Career self-assessment is seen as a permanent and integrative process, which is developed for the purpose of promoting educational quality, through value judgments, providing bases for decision-making (see Figure 1).

This process constitutes a cycle of continuous improvement, since the need of the program or career becomes a commitment. It requires reviewing, deciding and then acting (planning), followed by a process of revision of the whole evaluation for the purpose of improving it in future applications (meta-evaluation).

This phase of action is followed by a new phase of observation to determine how much and how the program has improved and what the new challenges are, starting a new cycle (the circle of quality). The steps are followed repeatedly in an upward or spiral way, because each new cycle means growth in time and a continuous improvement towards expected quality.

The evaluations have to be informative. Information is a key element. An outstanding job of collecting and analyzing data will not achieve the purposes of an evaluation if the results are not effectively socialized with the university community, and taken into account when designing and executing the improvement plan.

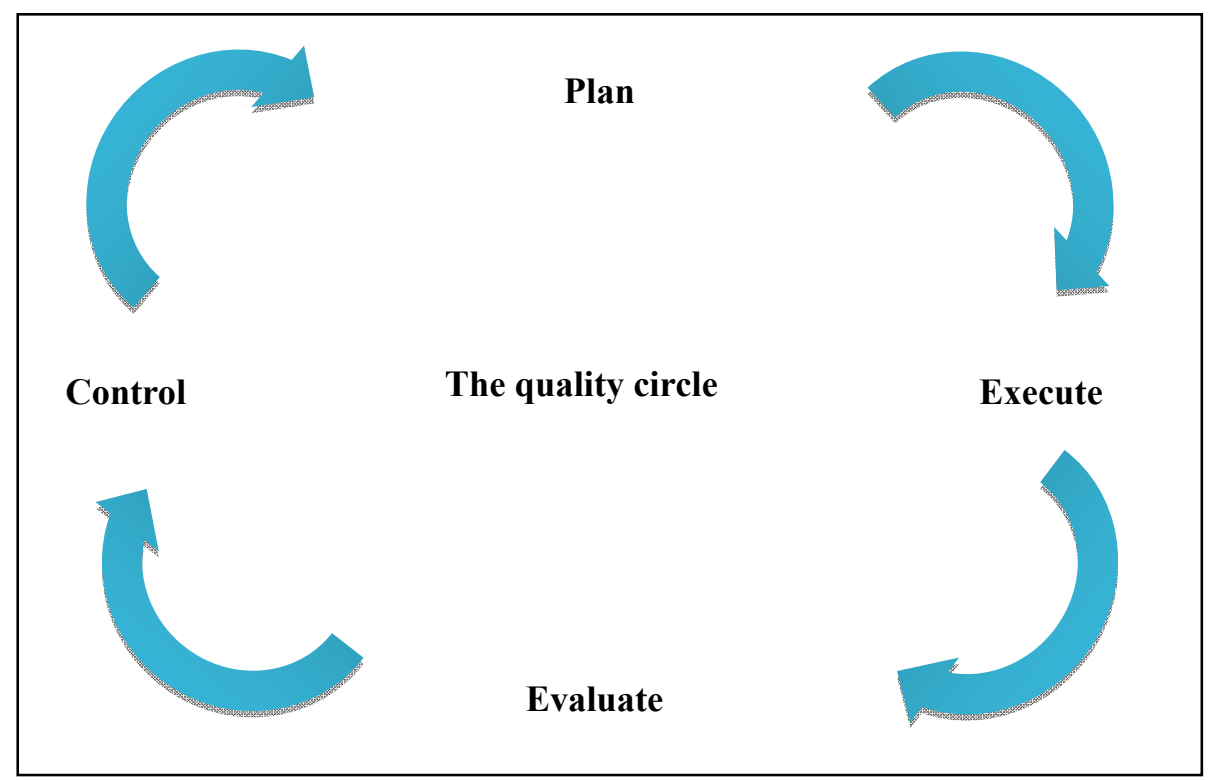

Figure 1. Quality circle (Source: Cohen \& Asín, 2014).

As one of the functions of the self-assessment area, the IGESCA of the UNED intends to implement meta-evaluation systematically in all self-evaluation processes of bachelor degrees or postgraduates, whether it is for accreditation or improvement purposes. For this project, three instruments were designed that are detailed below. They support the meta-evaluation, which takes into account the aspects proposed by the SINAES and others of interest to the institution, given the efforts which have been made to create the own quality criteria.

These instruments were analyzed and improved in order to implement them in the meta-evaluation of the computer engineering career.

For the SINAES, the meta-evaluation is understood as a systematic assessment of the self-evaluation process carried out by the careers. Its objective is to make a judgment about the quality or merits of the 
evaluation performed. Therefore, SINAES strongly recommends metaevaluation, although it is important to clarify that its exposition in the self-assessment report is not considered mandatory. Table 2 shows the aspects to be taken into account for the meta-evaluation.

Table 2

Relevant Aspects of the Meta-Evaluation

\begin{tabular}{|c|c|}
\hline Aspects & Contents \\
\hline $\begin{array}{l}\text { Information system and support } \\
\text { for decision-making }\end{array}$ & $\begin{array}{l}\text { Ease or difficulty for gathering requiered information. } \\
\text { University departments that support the self-evaluation process provided information in the } \\
\text { time required. } \\
\text { Veracity of the information collected from the support departments. }\end{array}$ \\
\hline Coordinating team & $\begin{array}{l}\text { Agreement designating the coordinatig team. } \\
\text { Profile of the members. } \\
\text { Suitability to attend self-evaluation and accreditation processes. } \\
\text { Capacity for teamwork. } \\
\text { Distribution of work among team members. }\end{array}$ \\
\hline Participation and involvement & $\begin{array}{l}\text { Level of motivation of academic, administrative, managerial, and student staff. } \\
\text { Sessions held and degree of participation of the attendees. } \\
\text { Opinion of all sectors of the career or programon the degree of participation. } \\
\text { Existence of a favorable organizational climate (openness, transparency, and democratic). }\end{array}$ \\
\hline Planning and organization & $\begin{array}{l}\text { Level of priority that the self-evaluation process had existence of a self-evaluation work plan } \\
\text { (schedule and activities). } \\
\text { Level of compliance of the activities, schedule, and people in charge. } \\
\text { Provisions to release those responsible for guiding the process. } \\
\text { Existence of a special university departmente to provide advice. } \\
\text { Clarity regarding the departments and functions of each one, during the accreditation process. }\end{array}$ \\
\hline Commitment & $\begin{array}{l}\text { Level of commitment of the higher authorities of the institution and of the career, teachers, and } \\
\text { students with the self-evaluation process reactivity. } \\
\text { Policies, agreements, and arrangements made to facilitate the self-evaluation process. } \\
\text { Opinion on the viability of proposals for improvement resources intended to implement the } \\
\text { improvement plan. }\end{array}$ \\
\hline Report & $\begin{array}{l}\text { Validation of the report by participants. } \\
\text { Quality of the self-assessment report presented. } \\
\text { Level of importance of proposed improvement actions. }\end{array}$ \\
\hline Sustainability & Policies and procedures that guarantee the permanence of the culture of self-evaluation. \\
\hline
\end{tabular}

Note. SINAES Accreditation Model and UNED guidelines (2011).

After analyzing the previous concepts on evaluation, self-evaluation, meta-evaluation, and others, the elaboration of the methodological proposal is explained in the following section.

\section{Methodological Proposal}

Once, the process carried out by the self-assessment commission (CAE, comisión de autoevaluación) of the computer engineering career ends, a meta-evaluation proposal of the process is carried out in order to systematize the experience, which in turn facilitates the re-accreditation of the career.

This proposal will be based on the SINAES Accreditation Model (2011) in addition to the guidelines established by the UNED, which contemplate the following points: (a) information system; (b) coordinating team; (c) participation and involvement; (d) planning and organization; (e) commitment; (f) the report; (g) sustainability over time; and (h) support for decision-making.

Three evaluation instruments made by the IGESCA are reviewed and adapted to comply with the aspects mentioned above, which are detailed in the following section. 
The resulting evaluation instruments are validated by the following participants: (a) research staff SINAES; (b) advisors of self-evaluation of IGESCA; and (c) representative sample of staff that has been involved in self-assessment processes within the university.

In order to continue with the implementation proposal, the instrument is validated by a sample of 20 professionals linked to the self-evaluation processes carried out at the university. The instruments to be applied are described next, in order to establish the criteria that will be used in the proposal to implement the meta-evaluation in the computer engineering career.

\section{Instruments to be Applied}

These instruments were initially taken from the IGESCA. They were evaluated, redesigned, and adapted to create the criteria to be considered that encompass the theory produced by the documentary analysis carried out, in order to comply with the aspects that meta-evaluation experts define as essential in the process. For the purposes of this research, the terms defined by SINAES are taken as follows:

1. Poor: The criterion is not met or there are precarious advances;

2. Insufficient: There are efforts that indicate an approximation to the fulfillment of the criterion but they are insufficient;

3. Acceptable: Compliance with the criterion is adequate although there are minor aspects that need to be improved;

4. Satisfactory: Compliance with the criterion is fully in line with SINAES requirements (SINAES, 2010, p. 30).

\section{Checklist to Evaluate the Compliance of Actions and Established Guidelines}

The objective is to obtain the perception of the members of the CAE on the degree of fulfillment of the different stages in the development of the self-evaluation report. The instrument was designed to be applied to members of the CAE of the career of informatic engineering, who must assign a value from 1 to $4(1=$ "Deficient," 2 = "Insufficient," 3 = "Acceptable," and 4 = "Satisfactory"), to rate each of the aspects referred to the self-assessment process listed in Table 3. The rating should be placed in the second column.

\section{Checklist on the Application of Quality Standards for Evaluation}

The objective is to obtain the perception of the members of the CAE on the degree of compliance with the internationally established standards for measuring the quality of educational of Career and Program evaluations. The instrument was designed to be applied to the members of the CAE of the Computer Engineering Career, who must assign a value from 1 to 4 ( 1 = "Deficient," 2 = "Insufficient," 3 = "Acceptable," and $4=$ "Satisfactory"), to rate each of the aspects related to the process of Self-assessment tools listed in Table 4. The rating should be placed on the second column.

\section{Checklist on Quality Characteristics of Self-Aassessment Process}

The objective is to identify the perception of CAE members on key aspects of the self-assessment process. The instrument was designed to be applied to the members of the CAE of the Computer Engineering Career, who must assign a value from 1 to $4(1$ = "Deficient," 2 = "Insufficient," 3 = "Acceptable," and $4=$ "Satisfactory"), to rate each of the aspects referred to the self-assessment process listed in Table 5. The rating should be placed on the second column. 
Table 3

Instrument 1: Checklist of the Evaluation of the Compliance of Actions and Established Guidelines

Institutional Guidelines Compliancefrom 1 to 4

1. The self-evaluation process emerges as a felt need within the program.

2. The self-evaluation process was included in the operational plan of the career.

3. A commission was established with time and functions assigned to its members.

4. Adequate training was received by the members of the CAE for the self-evaluation process.

5. Counseling by IGESCA is agreed on and endorsed.

6. The IGESCA adviser provides training to the commission.

7. The commission elaborates a working methodology to comply with the self-assessment and subsequent accreditation.

8. The commission submits the methodology of work proposed by the CAE to validation.

9. The commission received support from the School Dean to comply with the work methodology proposed by the CAE

10. The IGESCA advises the methodological processes for the collection of information, the analysis of data and the presentation of the report.

11. Institutional support was received from the other offices involved and necessary for the self-evaluation process for accreditation.

12. Availability of data and quantitative information required for the self-assessment process.

13. The information collected was sufficient to support value judgments that were issued in the report.

14. Inconsistencies detected in the information collected from different departments.

15. The self-assessment report was carried out according to the established methodology.

16. The commission socializes the results of the report with the other career members involved.

17. The commission incorporates the significant contributions of the different participants involved in the self-evaluation process.

18. The commission elaborates a plan of improvement for the career.

19. The School Dean presents a self-evaluation report and improvement plan to the academic vice-rector.

20. The institutional authorities endorse the commitment to improvement.

Note. Own elaboration based on quality criteria of SINAES and IGESCA (2017).

Table 4

Instrument 2: Checklist of the Application of Quality Standards for Evaluation

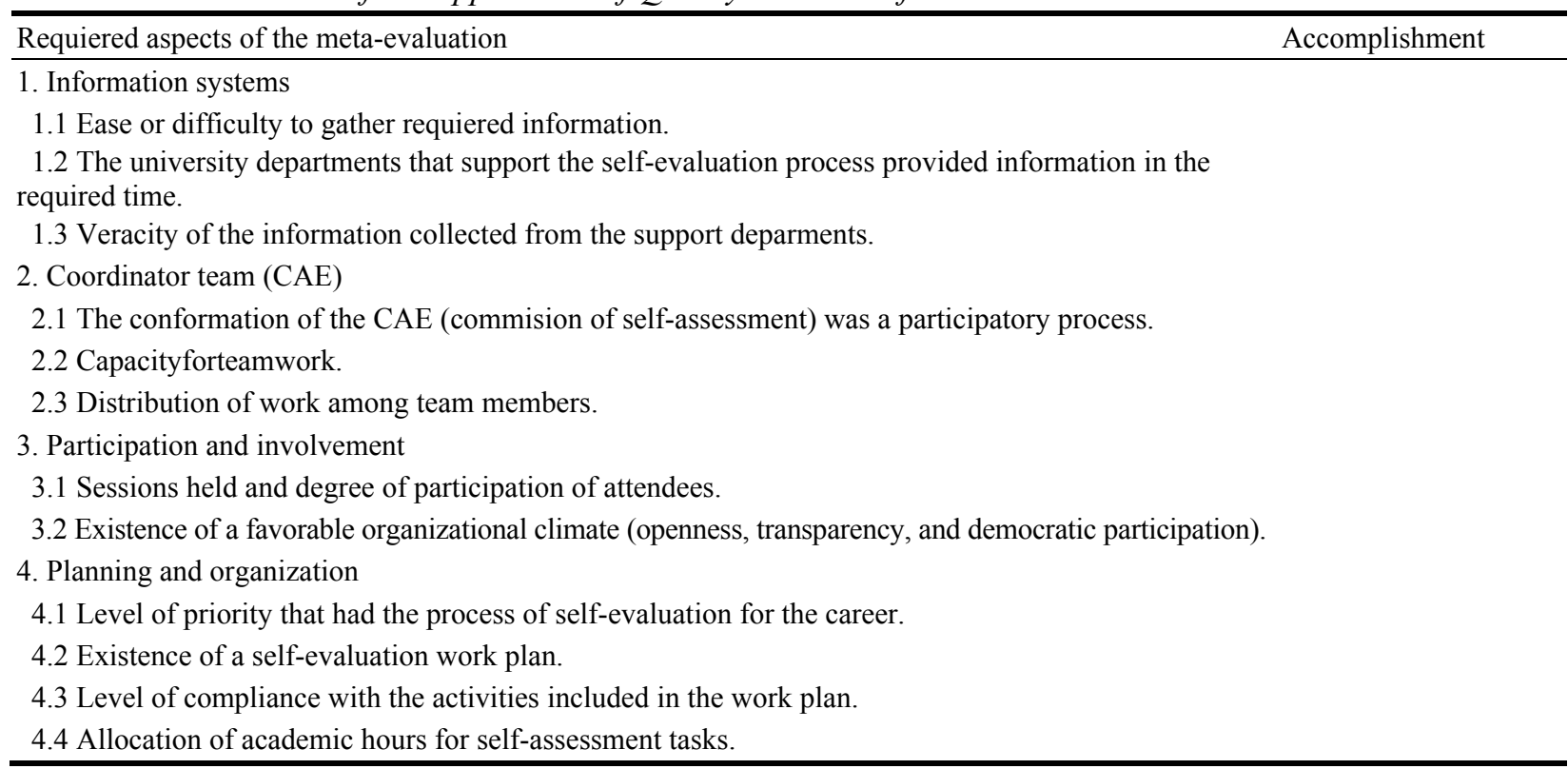


(Table 4 to be continued)

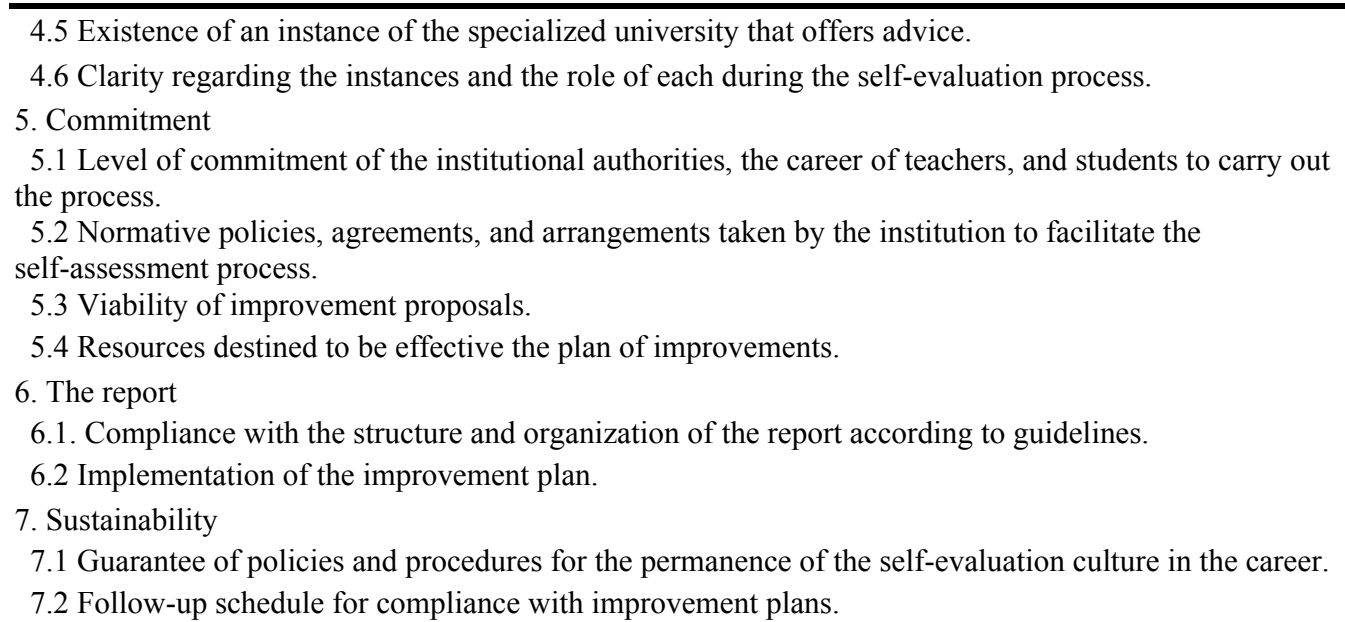

7.2 Follow-up schedule for compliance with improvement plans.

Note. Own elaboration based on quality criteria of SINAES and IGESCA (2017).

Table 5

Instrument 3: Checklist of Quality Characteristics of Self-Assesment Process

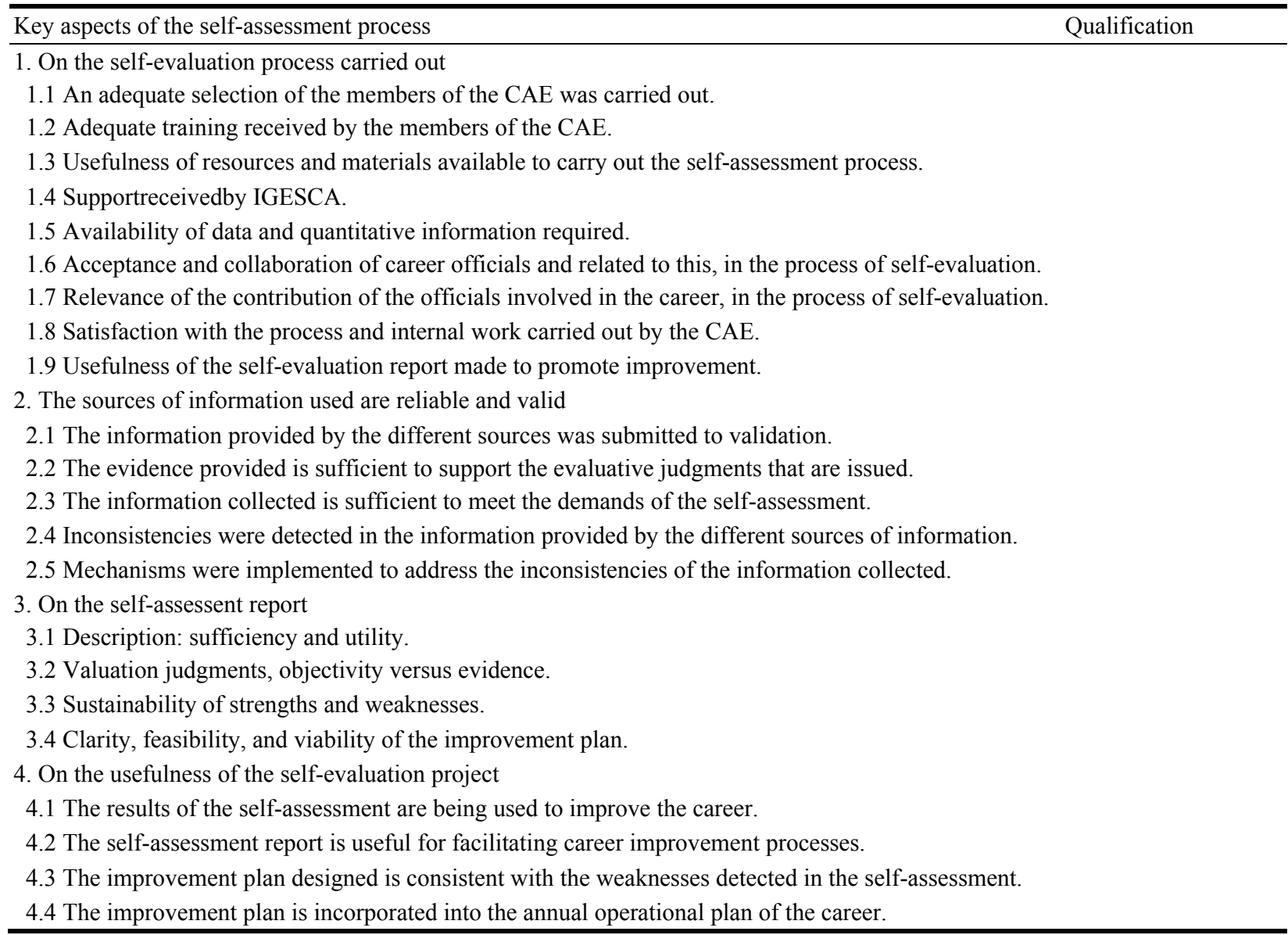
Note. Own elaboration based on quality criteria of SINAES and IGESCA (2017).

Once, the instruments that will be used in the implementation of the meta-evaluation in the career of computer engineering have been depicted, relevant aspects are described as follows. The first step was to 
validate these three instruments with specialists before their application to the people who participated in the Self-evaluation process of CAE.

The objective is to collect the information through the application of these three instruments by means of an online survey. Once, the information is collected, it is analyzed and results are obtained.

\section{Results Obtained From the Validation of the Instruments}

Some suggestions were obtained from the professionals in charge of the validation of instruments, such as change of some terms, wording of items, and inclusion of some others. They were corrected and validated again with the same experts who gave their approval, and continued with the design and socialization of the meta-evaluation proposal.

\section{Design and Socialization of the Meta-Evaluation Proposal}

The proposal for a meta-evaluation of the process contemplates the eight points mentioned above: information system, support for decision-making, coordinating team, participation and involvement, planning and organization, commitment, the report, and sustainability over time.

These eight themes will be evaluated in the three evaluation instruments made by the authors who adapted them for the computer engineering career, so that once these instruments are validated, they will be applied.

The Lyme survey tool is used for online application to collect the required information and then perform an analysis of the data. In addition, the meta-evaluation process is structured and developed in five stages:

Phase I: Formalization and organization of the process. 1. The decision to propose the meta-evaluation process is made once the computer engineering career has been accredited; and 2. The meta-evaluation proposal begins.

Phase II: Planning the implementation of the meta-evaluation. 1. The beginning and the scope of the process are communicated to stakeholders and institutional authorities; 2 . The instruments detailed are used for the purpose mentioned; 3 . The various meta-evaluation activities are distributed and assigned among those involved in the process; 4 . The schedule of activities is defined; 5. The required resources are determined: human, budgetary, material, among others; and 6. Methodological strategies that will be used in the meta-evaluation are defined.

Phase III: Execution. 1. Validation of the instruments of data collection; 2. Definition of the samples; 3. Collection of the information; and 4. Processing of the information

Phase IV: Assessment. 1. Reflective, critical, and participatory analysis of the information and data collected; and 2. Assessment of information collected based on the SINAES Model (2011) regarding meta-evaluation.

Phase V: Elaboration of the report. 1. A meta-evaluation report will be prepared based on the analysis of the information collected; 2. Socialization of results with institutional authorities; 3 . The results obtained in terms of strengths and weaknesses are released in order to translate weak points into improvement opportunities for future self-evaluation processes which will be carried out in other university careers; 4. Replicate the meta-evaluation in other careers, which have been accredited in the university and have not carried out that process; and 5. Follow up on other meta-evaluations that are carried out in the future in order to incorporate their results into the continuous improvement of the institution.

In order to implement the meta-evaluation, it is necessary to create a schedule that describes the tasks to be performed to achieve the goal. 


\section{Implementation Schedule}

The implementation schedule is detailed in Table 6.

Table 6

Schedule to Implement

Meta-evaluation proposal for the computer engineering career

\begin{tabular}{|c|c|c|c|c|c|c|c|c|c|c|c|c|c|c|c|c|}
\hline \multirow{3}{*}{$\begin{array}{l}\text { Calendar activities } \\
\text { Start date }\end{array}$} & \multicolumn{16}{|c|}{ III quarter 2017} \\
\hline & \multicolumn{4}{|c|}{ September } & \multicolumn{5}{|c|}{ October } & \multicolumn{4}{|c|}{ November } & \multicolumn{3}{|c|}{ December } \\
\hline & 4 & 11 & 18 & 25 & 2 & 9 & 16 & 23 & 30 & 6 & 13 & 20 & 27 & 4 & 11 & 18 \\
\hline
\end{tabular}

Preparation prior to the meta-evaluation

process

Required logistics

Meta-evaluation process initiation

Process initiation

Socialization of the meta-evaluation

proposal

Socialization workshop

Application of the instruments

Invitations are sent in Lyme survey

Designation of person in charge of

monitoring

Survey monitoring

Closing survey

Collection of the information

Transfer of the information to a

statistical programm

Information processing

Obtaining results

Analysis of results

Analysis of the information collected

Issuance of conclusions and

recommendations

Issuance of the report with conclusions

and recomendations

Preparation of report of results

Socialization of the report with the CAE

Organization of the socialization

workshop

Search for necessary resources

Workshop on socialization and closure

of the activity

Socialization workshop report

Presentation of results to the university authorities

Attend a hearing before the university authorities to present the

meta-evaluation report in conjunction

with the results of the Workshop

\begin{tabular}{|l|l|l|l|l|l|l|l|l|l|l|l|l|l|l|} 
&
\end{tabular}

(1)


Once, the activities set out in the schedule have been carried out, the results will be socialized with the institutional authorities, so that the meta-evaluation carried out in the computer engineering career will serve as an example and guide for other accredited university degrees, thus, making it a permanent activity for continuous improvement of evaluation processes.

\section{Results}

An active participation of the professionals who participated in the validation of the instruments was obtained. They considered that the instructions and wording of the questions is adequate, and cover the important aspects to be evaluated.

On one hand, the process was enriched by the support obtained from the professionals who participated in the validation of the instruments, their valuable contributions and feedback, and their willingness to collaborate on future projects dealing with similar topics. On the other hand, there was a favorable consent on the part of the institutional authorities, the computer engineering career, and IGESCA authorities for the implementation and results of the project.

Another important result is the innovative initiative to meta-evaluate the self-evaluation processes for graduate and postgraduate degrees accredited for the improvement of these processes, since they have not been previously carried out.

But undoubtedly, the best result was the development of the instruments to be applied in the meta-evaluation to gather the necessary information, which will be input to be used byaccredited careers that are subject to the meta-evaluation processes. That is, with this meta-evaluation proposal, the institution has an established procedure for future processes to be carried out.

\section{Conclusions}

Based on the results and considering the purpose of identifying the opinion of the professionals surveyed, it can be said that involving academics, students, and authorities in the meta-evaluation process will allow to detect favorable and unfavorable experiences.

University authorities have considered it important to implement the meta-evaluation in the career, because it will serve as input to determine the strengths, weaknesses, and limitations of the self-evaluation processes. This information will be incorporated into institutional development plans, which, in turn, allows university improvement.

That is, strengths and weaknesses are incorporated, planned, and developed as activities or goals to be fulfilled which, in turn, become development strategies. Most importantly, it is given human, technological or budgetary resources, among others, to achieve its compliance and sustainability over time.

Meta-evaluation is a resource or a practical alternative to any discrepancies that may arise after an evaluation.

Another important point to consider is that, to this date, no meta-evaluation has been carried out in any of the accredited careers or programs (21 in total) by SINAES or another accrediting agency, such as ACAP. Hence, it will produce results that may serve to facilitate and improve the self-assessment process of other careers before beginning their self-evaluation process, either for improvementor accreditation purposes. The following section details the recommendations obtained in this process. 


\section{Recommendations}

The meta-evaluation is an important social learning process for the University. Therefore, its application requires more than instruments designed with a list of criteria. The meta-evaluators are required to raise questions, suggestions, and perspectives to facilitate understanding of the process for both the evaluators and stakeholders. It is important to:

1. Socialize the proposal to accredited careers and other university officials, so that this process becomes a basis for future processes.

2. Request university authorities to provide resources to correct, improve, or turn the results obtained from the meta-evaluation conducted in the computer engineering career into opportunities for improvement.

3. Recommend IGESCA that the meta-evaluation be included within the functions performed by the self-assessment department, so that it may lead, advice, support, and accompany these processes, accredited careers, and programs.

4. To recommend university, authorities to provide IGESCA with the necessary resources, so that the meta-evaluation is included in the self-evaluation department of that institute as a regular activity within its functions.

\section{References}

Acón, A., \& Cañipa, P. (2017). Transition from distance to virtual education at the Universidad Estatal a Distancia of Costa Rica. In World Conference on Online Learning. Canada, Toronto.

Cohen, D., \& Asín, E. (2014). Traditional concepts of business management and administration: Information technology. Mexico: McGraw Hill/Interamericana Editores.

Díaz, L. F., \& Rosales, R. (2003). Meta-evaluación: Evaluación de la evaluación de políticas, programas y proyectos sociales (Meta-evaluation: Evaluation of the evaluation of policies, programs, and social projects). San José, Costa Rica: EUNED.

Elizalde, L., Pérez, C., \& Olvera, B. (2008). Meta-evaluación del proceso de evaluación docente: Universidad Autónoma del Estado de Hidalgo (Meta-evaluation of the teacher evaluation process: Autonomous University of the State of Hidalgo). Retrieved December 8, 2016, from http://www.redalyc.org/pdf/340/34005310.pdf

Informatics Career. (2017). Bachelor's degree: Distance State University. Retrieved Juanuary 16, 2017, from https://www.uned. ac.cr/ecen/carrera/ii/88

Instituto de Gestión de la Calidad Académica. (2017). Inicio. Retrieved February 14, 2017, from http://www.uned.ac.cr/ academica/igesca/inicio

La Gaceta. (2002). Ley del Sistema Nacional de Acreditación de la Educación Superior (Law of the National System of Accreditation of Higher Education, SINAES). Retrieved November 9, 2016, from http://derecho.ucr.ac.cr/sites/all/ documentos/Acreditacion/Normativa/ley_8256.pdf

La Gaceta. (2010). Fortalecimiento del Sistema Nacional de Acreditación de la Educación Superior (SINAES) (Strengthening the National Accreditation System for Higher Education). Retrieved November 10, 2016, from http://derecho.ucr.ac.cr/sites/all/ documentos/Acreditacion/Normativa/ley_8798_SINAES.pdf

Población de Costa Rica. (2017). History of the population of Costa Rica. Retrieved December 2, 2016, from http://countrymeters. info/es/Costa Rica

SINAES. (2009). Modelo de Acreditación Oficial de Carreras de Grado del Sistema de Acreditación de la Educación Superior (Official Accreditation Model for Degree Programs of the Higher Education Accreditation Stystem). Retrieved December 2, 2016, from http://www.sinaes.ac.cr/images/docs/proceso_acreditacion/manual_grado_09.pdf

SINAES. (2011). Official Accreditation Model for degree programs of the higher education accreditation system for distance modality. Costa Rica: Author.

SINAES. (2017). What is the SINAES? Legal framework. Retrieved October 13, 2016, from http://www.sinaes.ac.cr/index.php? option=com_content\&view=article\&id=2\&Itemid=103

State of the Nation. (2016). The evolution of higher education. Retrieved February 14, 2017, from http://www.estadonacion.or.cr/ educacion2015/assets/cap-4-ee-2015.pdf 
Stufflebeam, D. (2011). Meta-evaluation. Journal of Multi-Disciplinary Evaluation, 7(15), 99-158.

Universidad Estatal a Distancia (UNED). (2004). Ley de Creación (Creation law). Retrieved November 10, 2016, from http://www.uned.ac. cr/academica/images/Normativa/Ley_de_creacion.pdf

UNED. (2012). Plan de Desarrollo Académico 2012-2017 (Academic Develpment Plan 2012-2017). Retrieved September 23, 2016, from http://www.uned.ac.cr/academica/plan_academico/insumos/PlanDesAcad_UNED_final.pdf 